\title{
Supplement of "Rapid recirculation of FNPP1 derived radiocaesium suggesting new pathway of subtropical mode water in the western North Pacific to the Sea of Japan”
}

Yayoi Inomata $^{1}$, Michio Aoyama ${ }^{2}$, Yasunori Hamajima ${ }^{1}$, Masatoshi Yamada ${ }^{3}$

$5 \quad{ }^{1}$ Institute of Nature and Environmental Technology, Kanazawa University, Kanazawa, 920-1156, Japan

${ }^{2}$ Institute of Environmental Radioactivity, Fukushima University, Fukushima, 960-1296, Japan

${ }^{3}$ Institute of Radiation Emergency Medicine, Hirosaki University, Hirosaki, 036-8564, Japan

Correspondence to: Yayoi Inomata (yinomata@se.kanazawa-u.ac.jp) 
(a) Before 11 March 2011

10

15

20

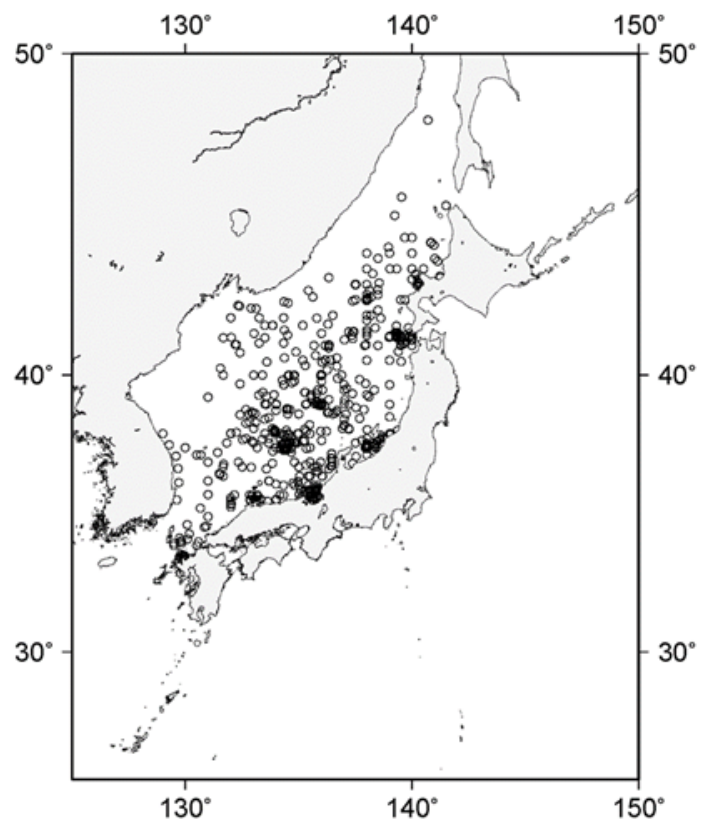

(b) After 11 March 2011

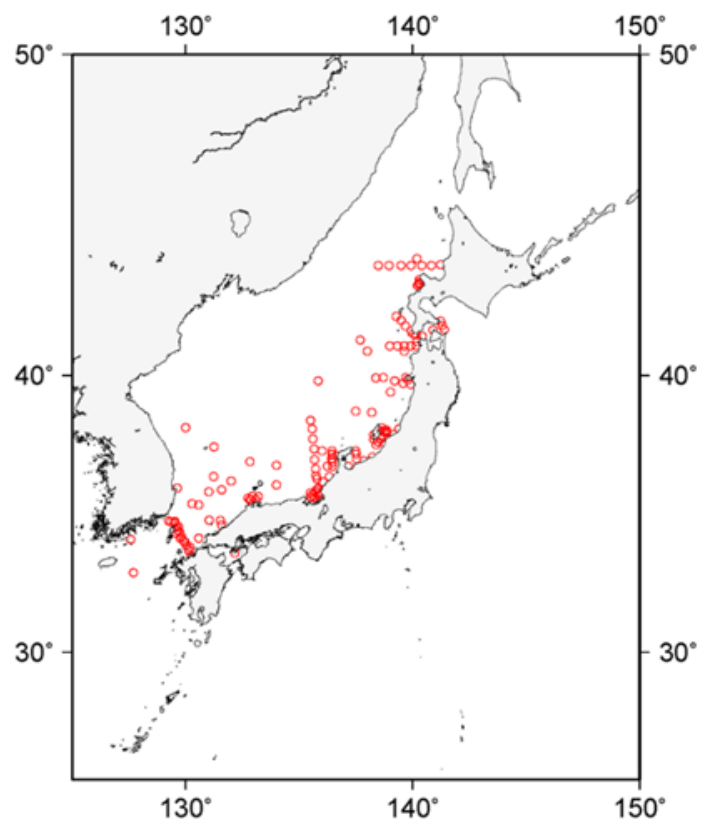

Fig. S1. ${ }^{137}$ Cs measurement sites (a) before 11 March 2011, (b) after 11 March 2011 in the Sea of Japan. The measurement data in the Sea of Japan were depicted. 


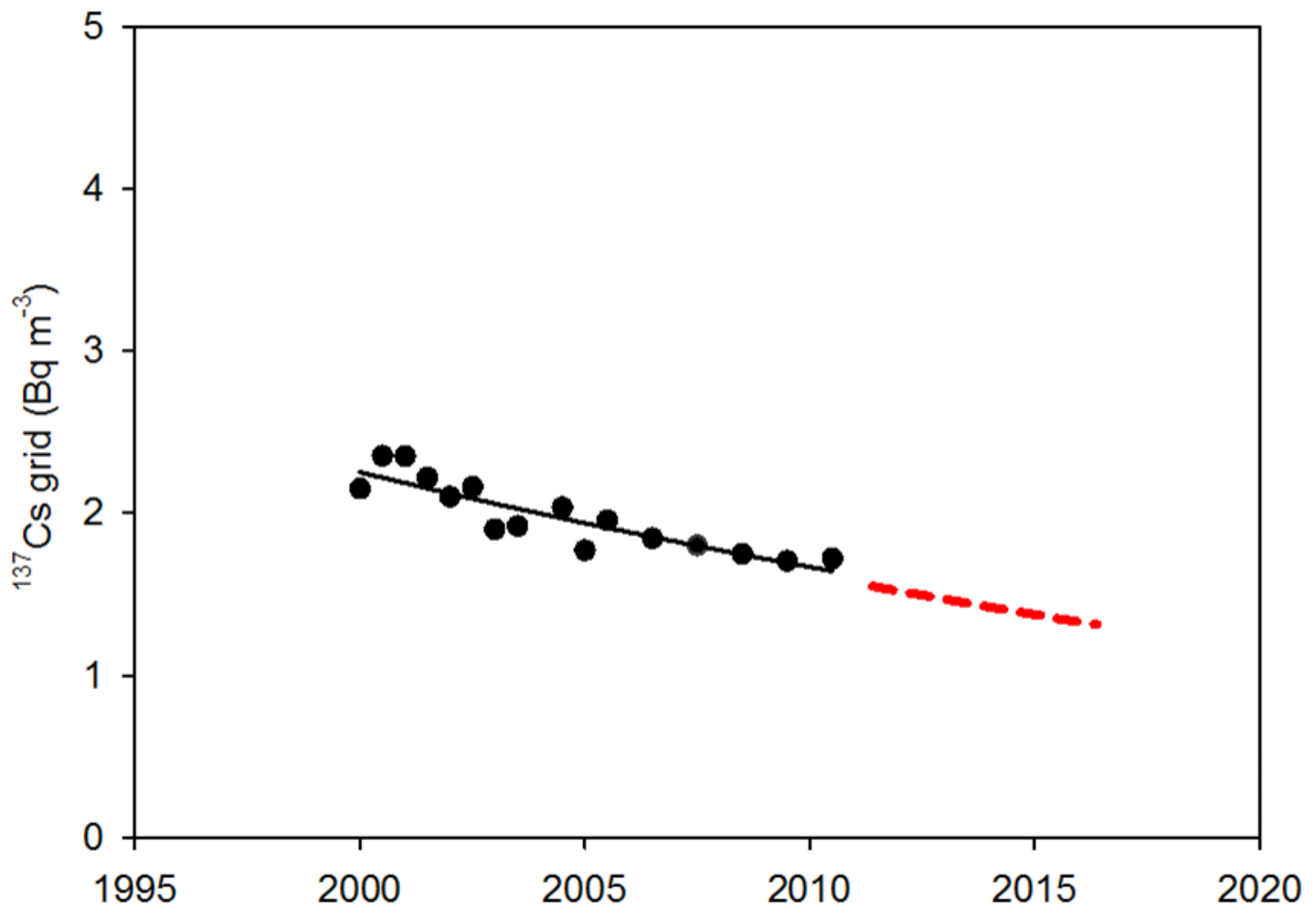

20

Fig. S2. The half-year average value of ${ }^{137}$ Cs activity concentrations from 2000 to 2010 . The value was decay corrected to $11{ }^{\text {th }}$ March 2011. Based on this fitting curve, ${ }^{137}$ Cs activity concentrations except for the FNPP1 origin were estimated. 


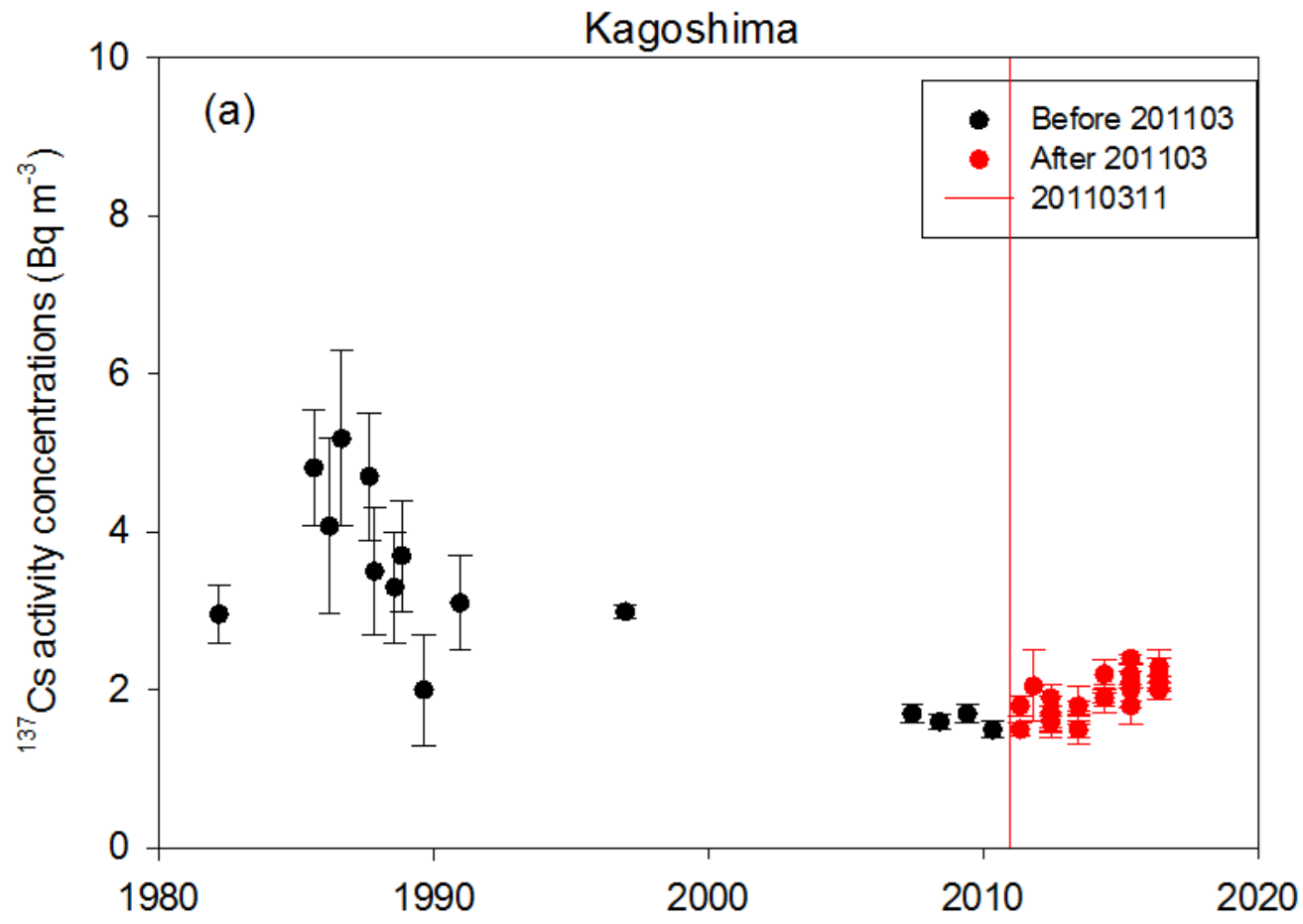

20

25

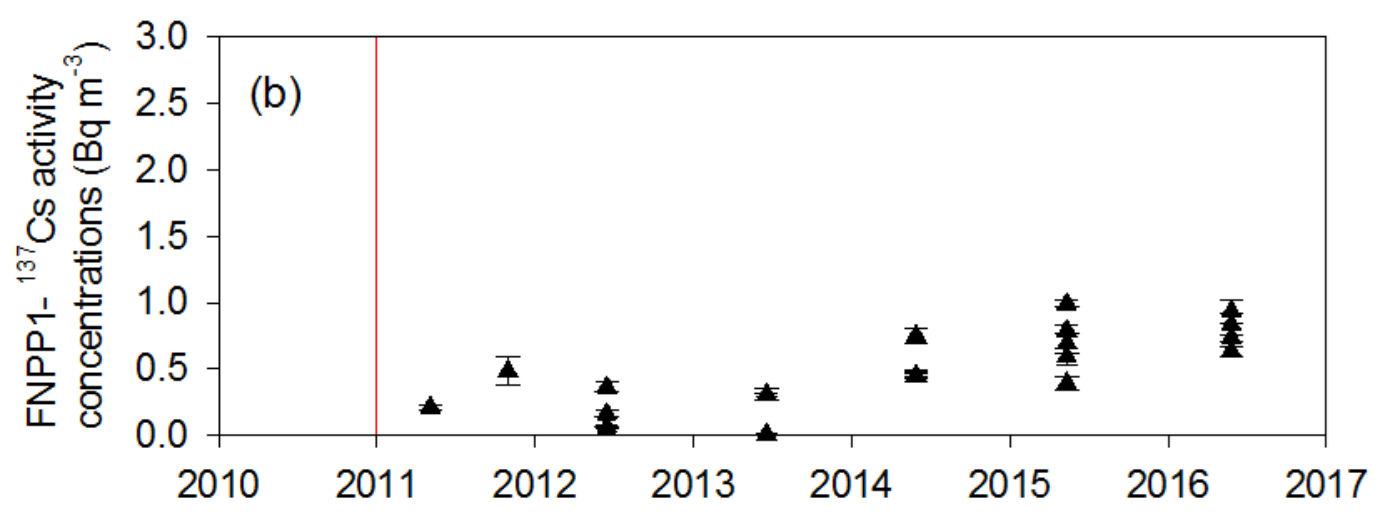

30 Fig. S3. Time variation of (a) ${ }^{137}$ Cs activity from 1980 to 2020, (b) FNPP1- ${ }^{137}$ Cs activity based on the fitting curve shown in Figure SI1 at Kagoshima. The value was decay corrected to $11^{\text {th }}$ March 2011. Vertical red line mean the FNPP1 accident day (11 March 2011). 


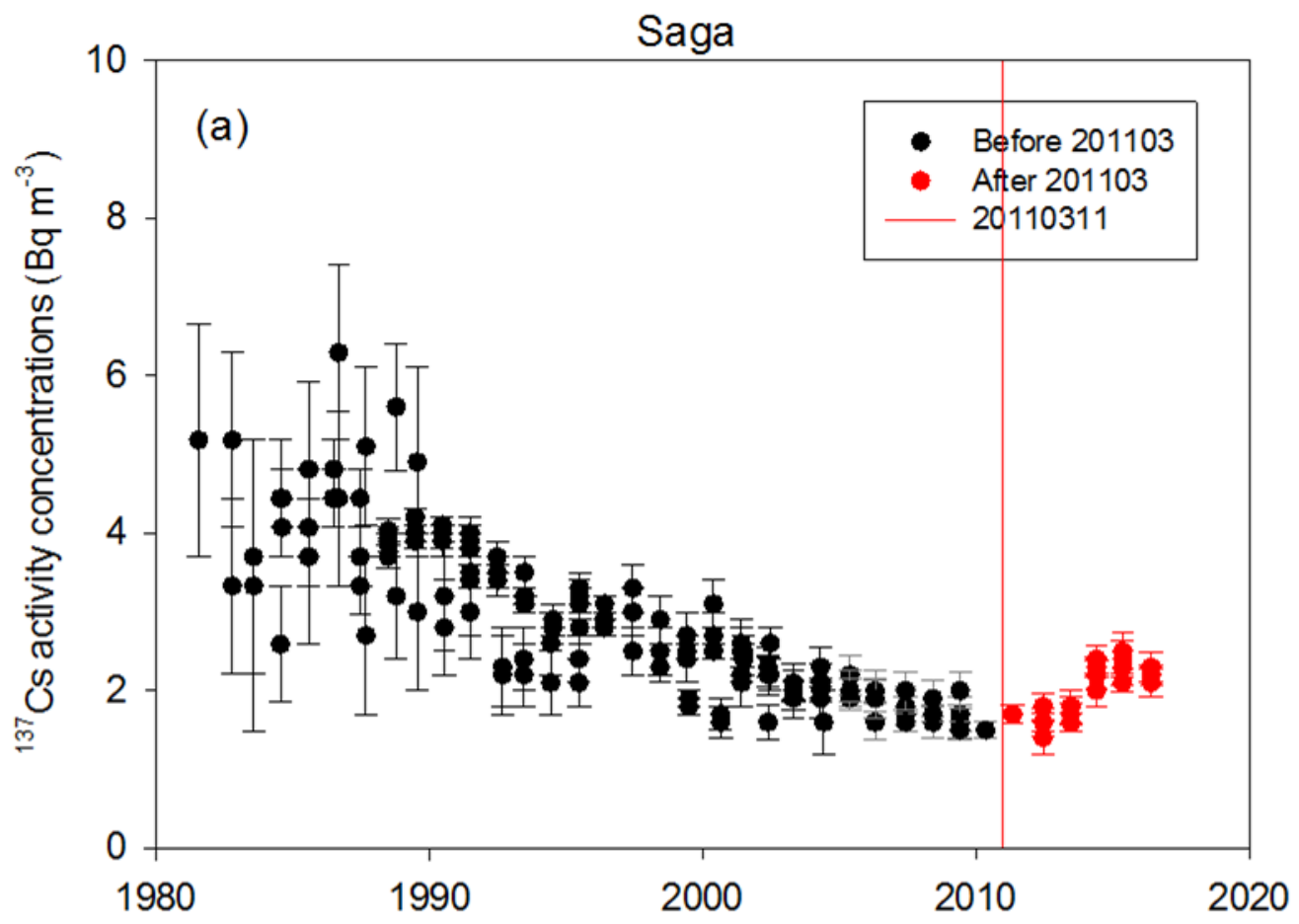

20

25

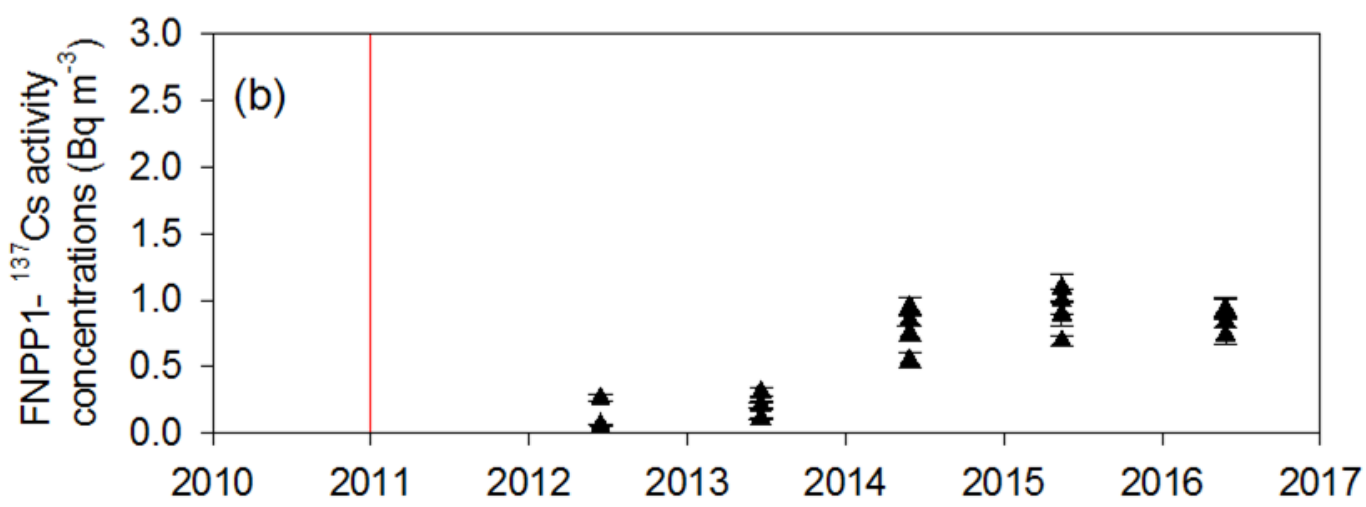

30 Fig. S4. Time variation of (a) ${ }^{137}$ Cs activity concentrations from 1980 to 2020, (b) FNPP1- ${ }^{137}$ Cs activity concentrations based on the fitting curve shown in Figure SI1 at Saga. The value was decay corrected to $11^{\text {th }}$ March 2011.Vertical red line mean the FNPP1 accident day (11 March 2011). 


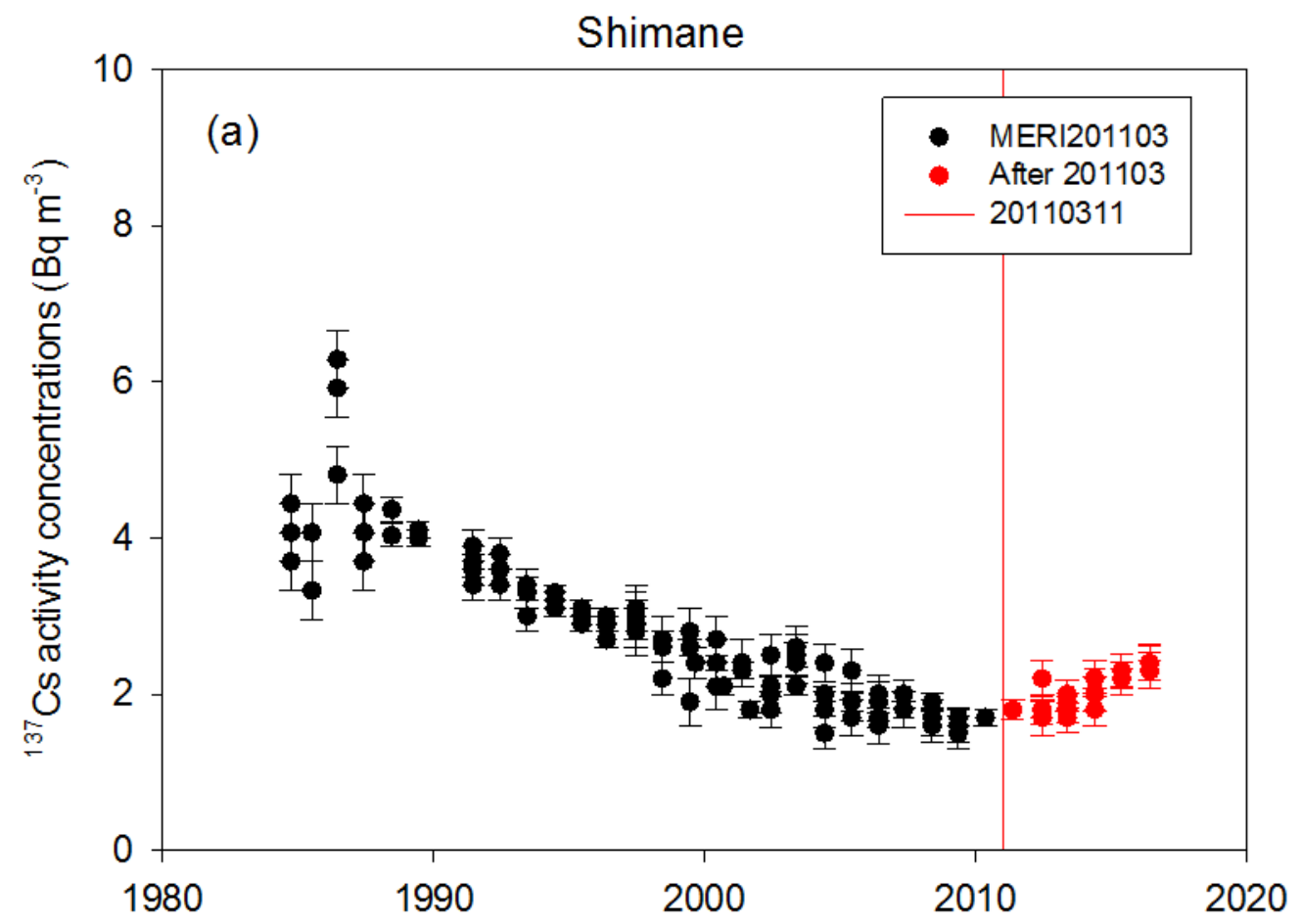

20

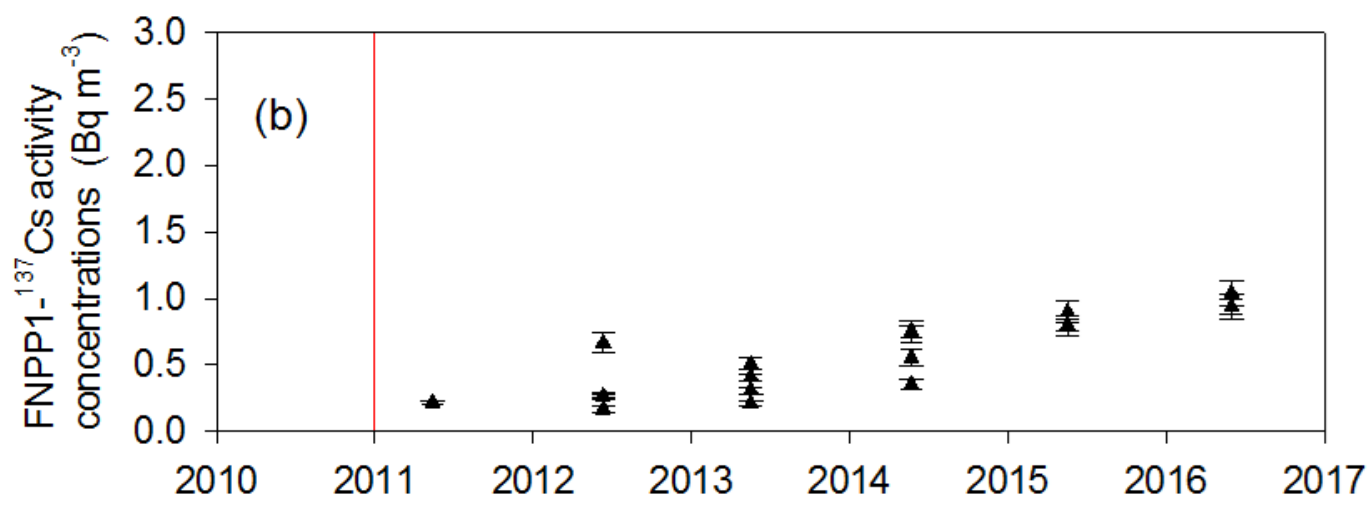

Fig. S5. Time variation of (a) ${ }^{137}$ Cs activity concentrations from 1980 to 2020, (b) FNPP1 ${ }^{137}$ Cs activity

30 concentrations based on the fitting curve shown in Figure SI1 at Shimane. The value was decay corrected to $11^{\text {th }}$ March 2011.Vertical red line mean the FNPP1 accident day (11 March 2011). 
Fukui

10

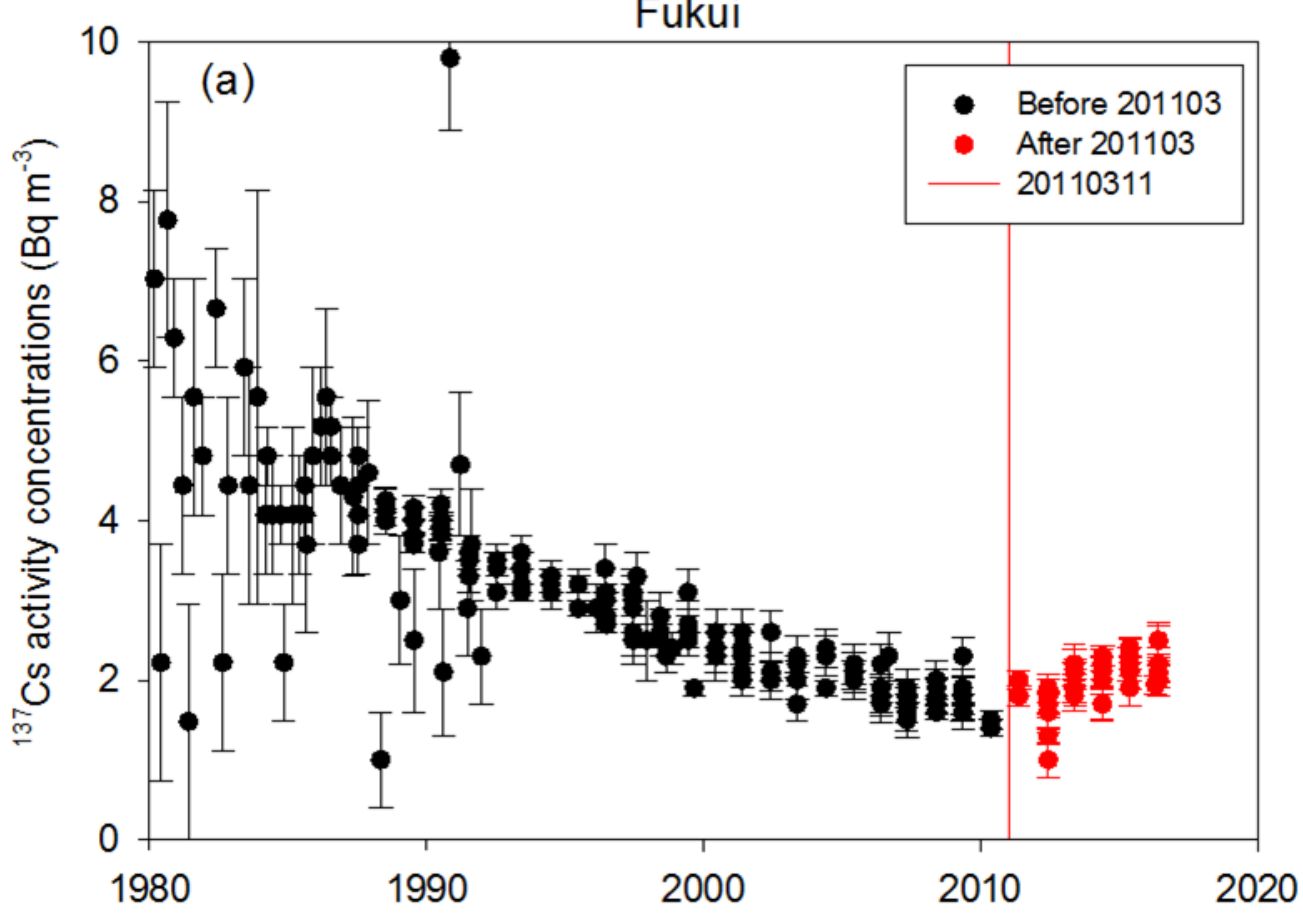

20

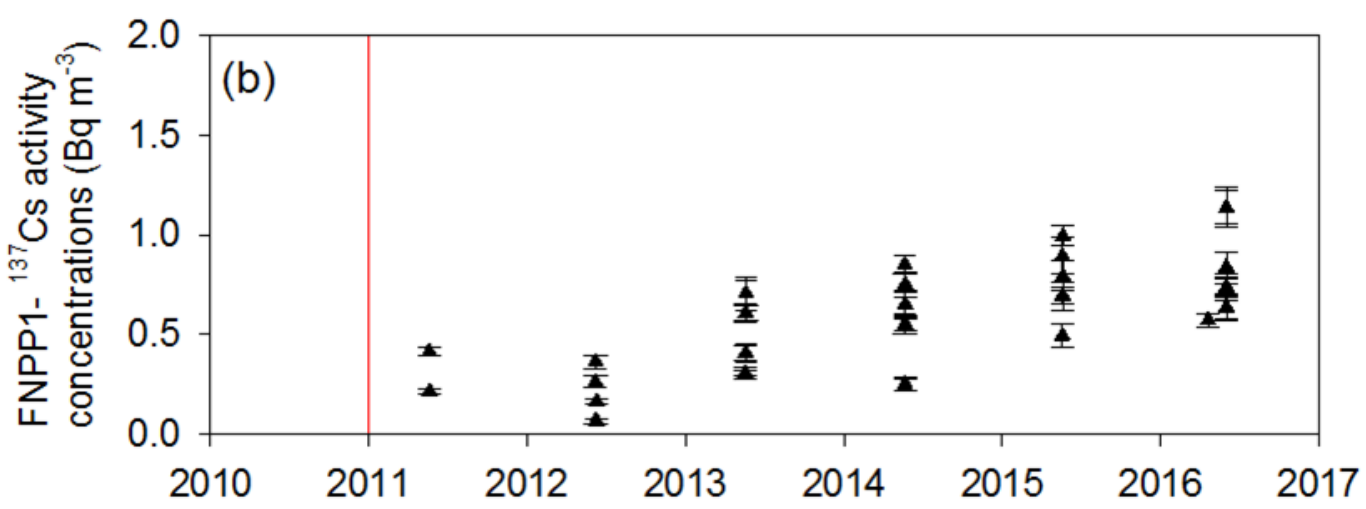

30 Fig. S6. Time variation of (a) ${ }^{137}$ Cs activity concentrations from 1980 to 2020, (b) FNPP1- ${ }^{137}$ Cs activity concentrations based on the fitting curve shown in Figure SI1 at Fukui. The value was decay corrected to $11^{\text {th }}$ March 2011. Vertical red line mean the FNPP1 accident day (11 March 2011). 


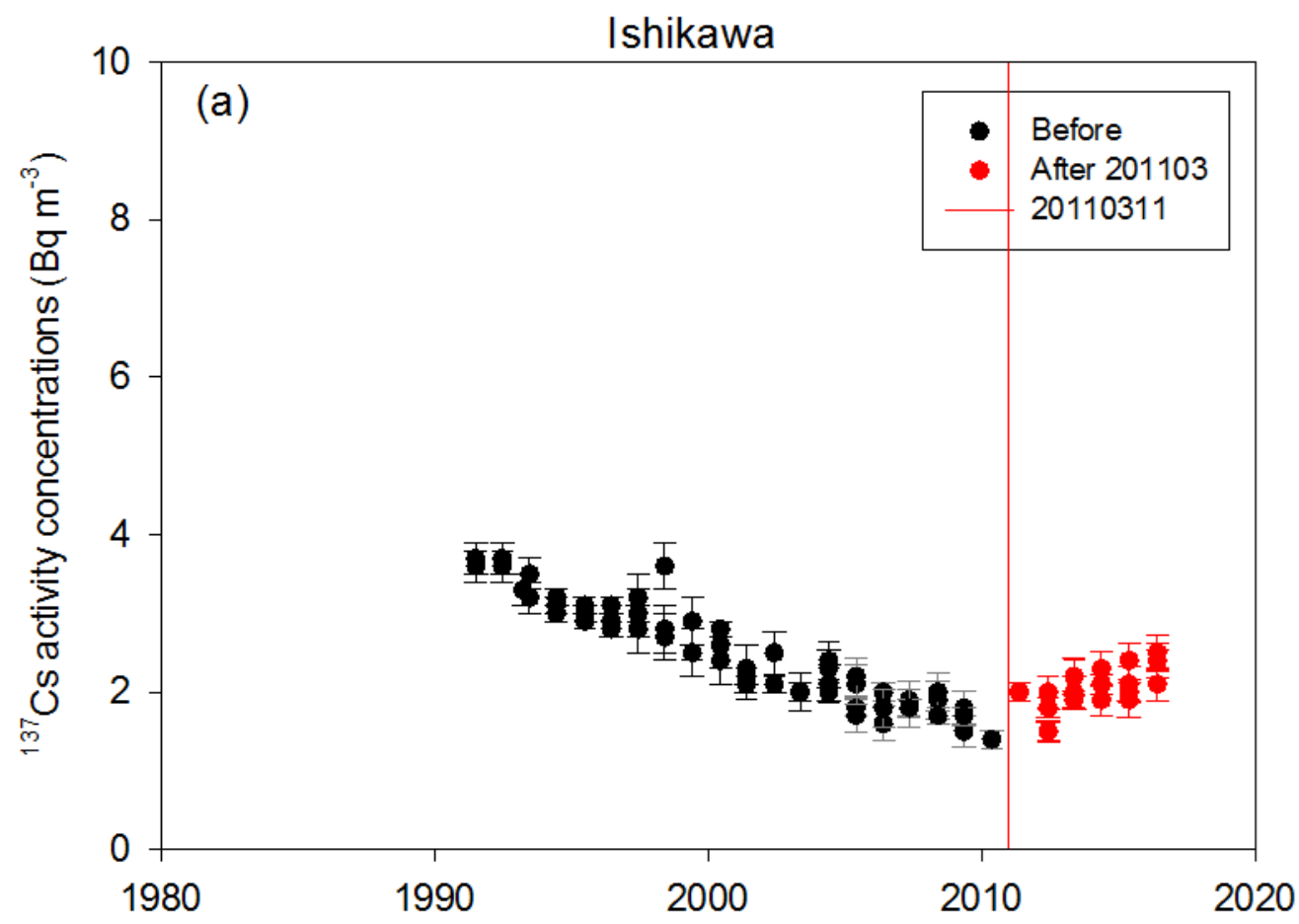

20

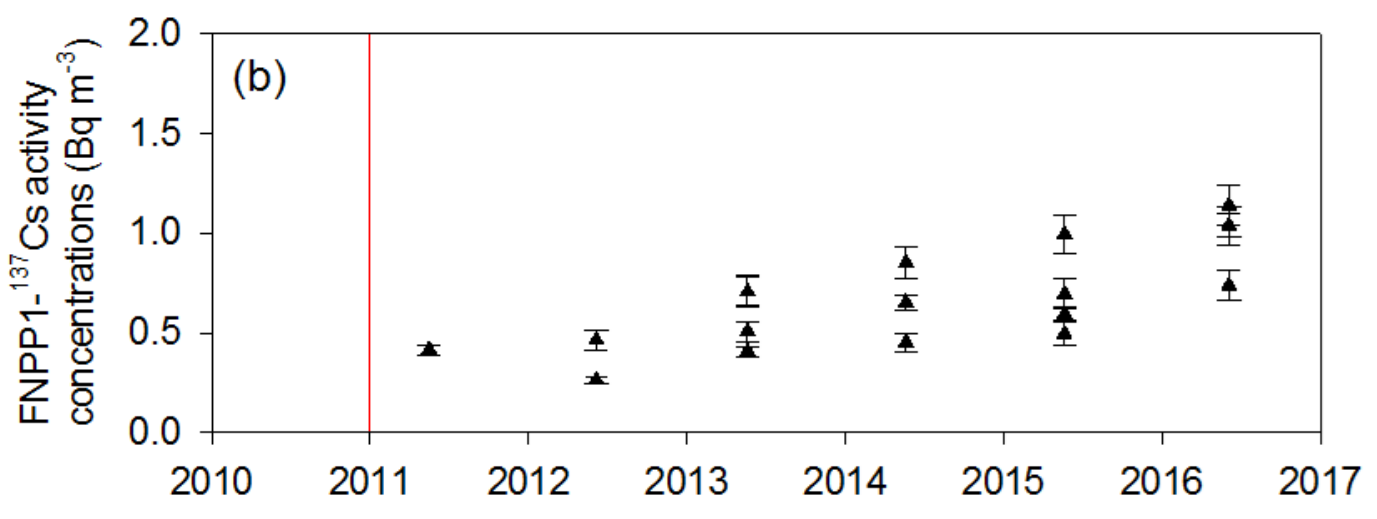

30

Fig. S7. Time variation of (a) ${ }^{137}$ Cs activity concentrations from 1980 to 2020, (b) FNPP1- ${ }^{137}$ Cs activity concentrations based on the fitting curve shown in Figure SI1 at Ishikawa. The value was decay corrected to $11^{\text {th }}$ March 2011.Vertical red line mean the FNPP1 accident day (11 March 2011). 
Niigata

10

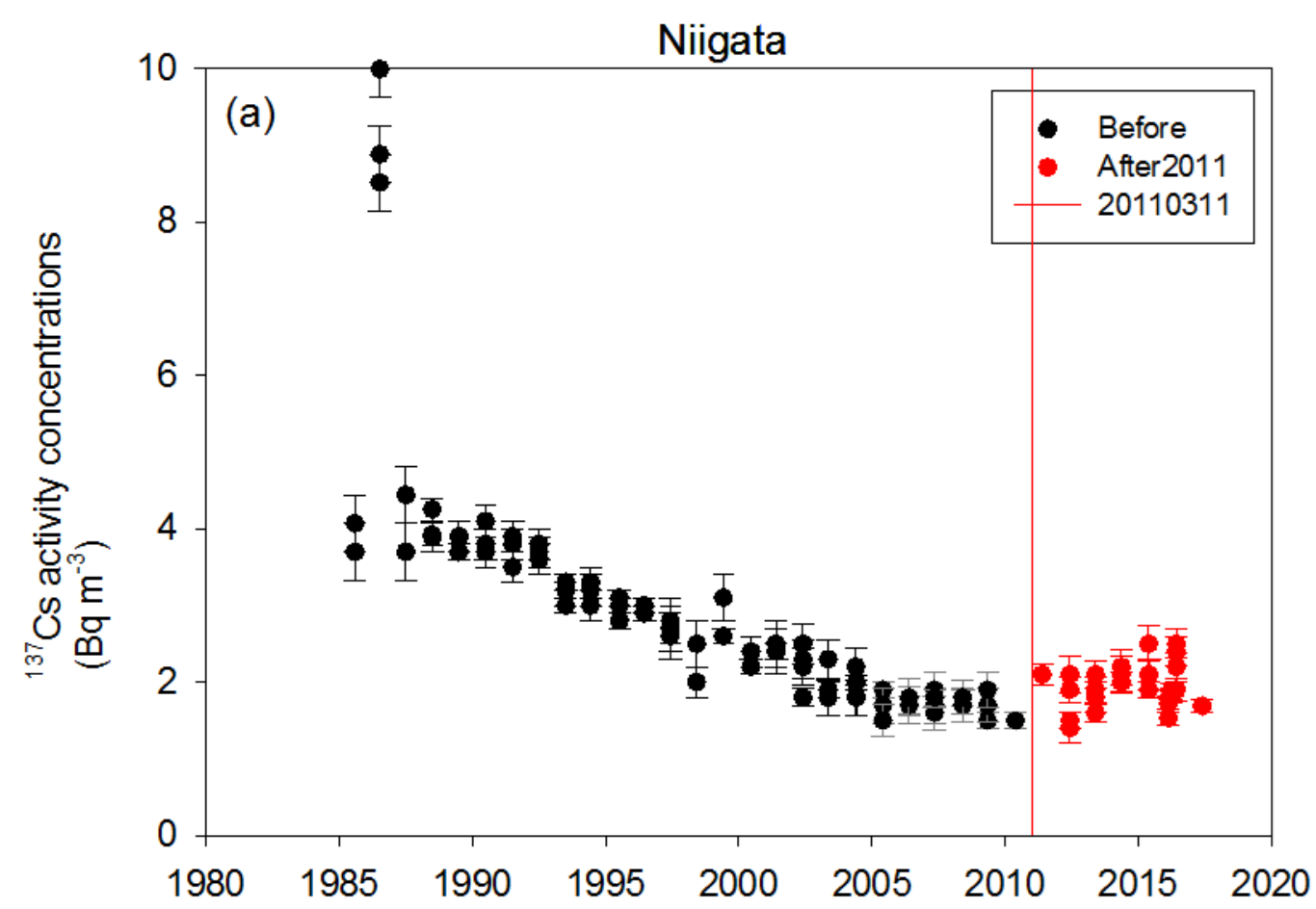

20

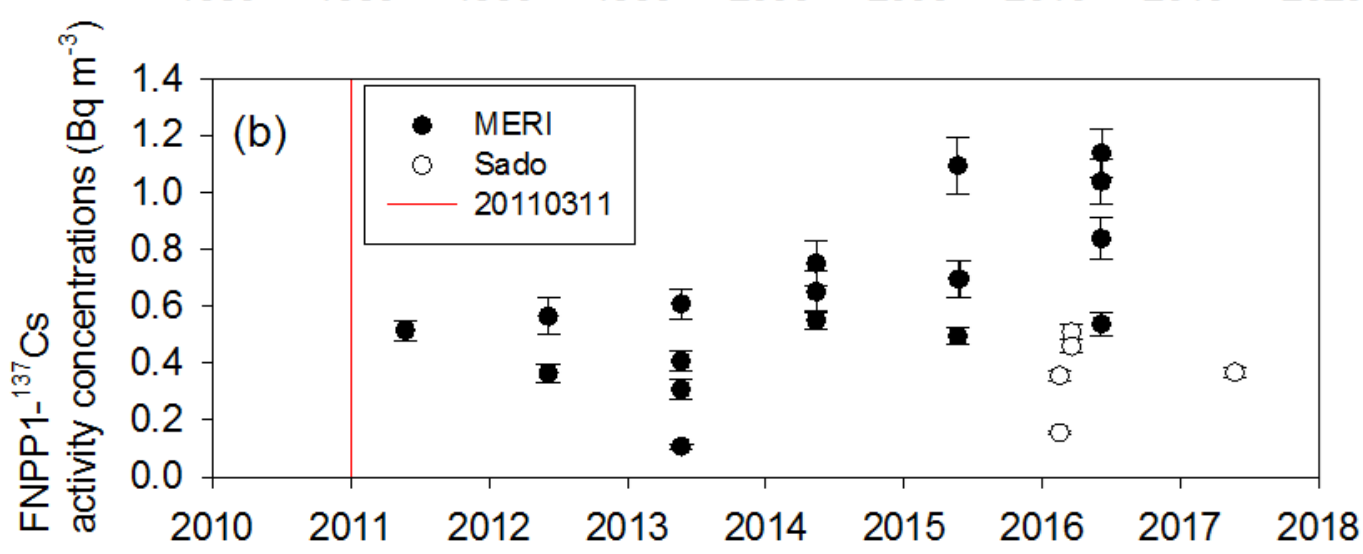

30 Fig. S8. Time variation of (a) ${ }^{137}$ Cs activity concentrations from 1980 to 2020, (b) FNPP1- ${ }^{137}$ Cs activity concentrations based on the fitting curve shown in Figure SI1 at Niigata. The value was decay corrected to $11^{\text {th }}$ March 2011. Vertical red line mean the FNPP1 accident day (11 March 2011). 


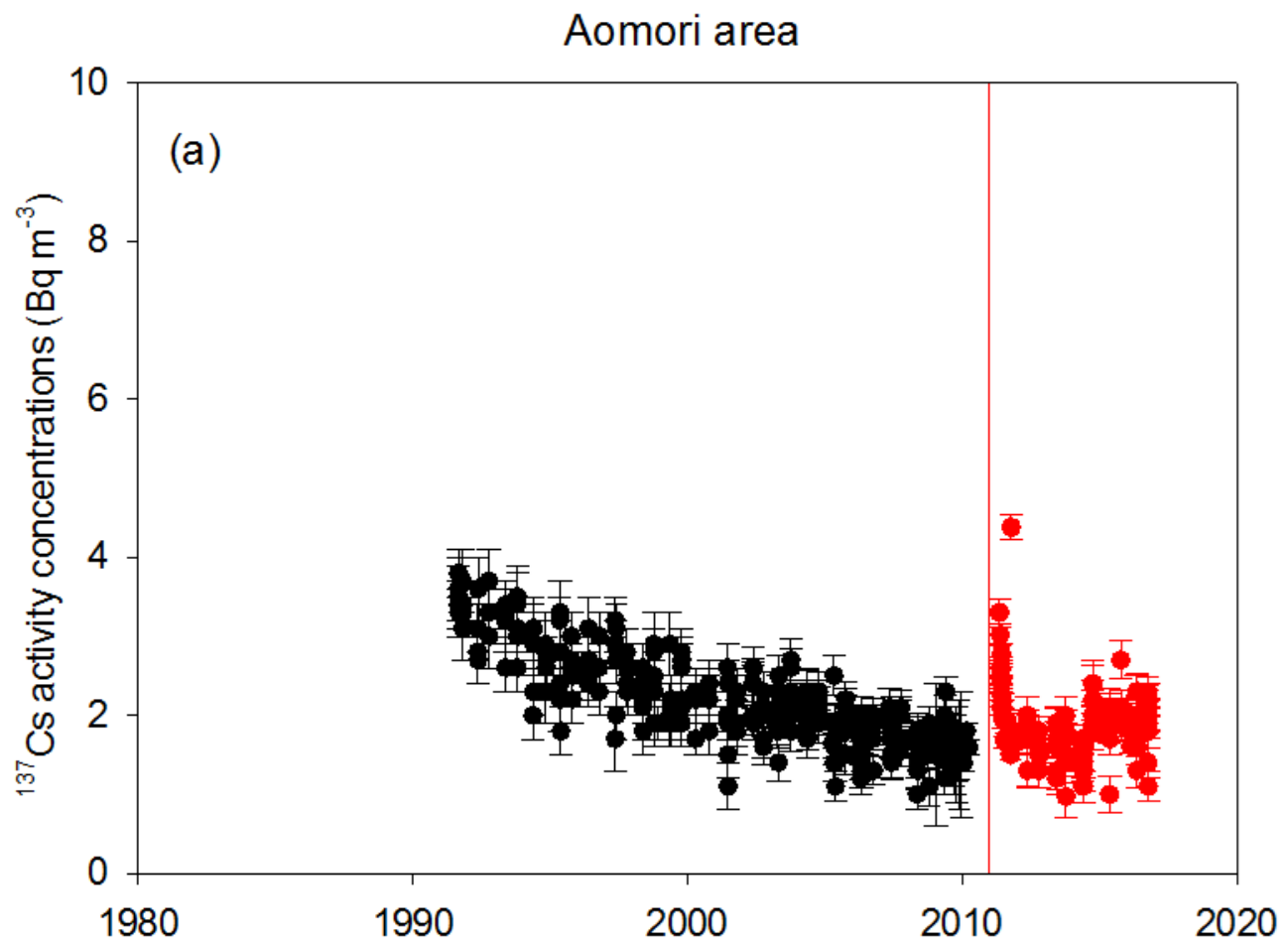

20

25

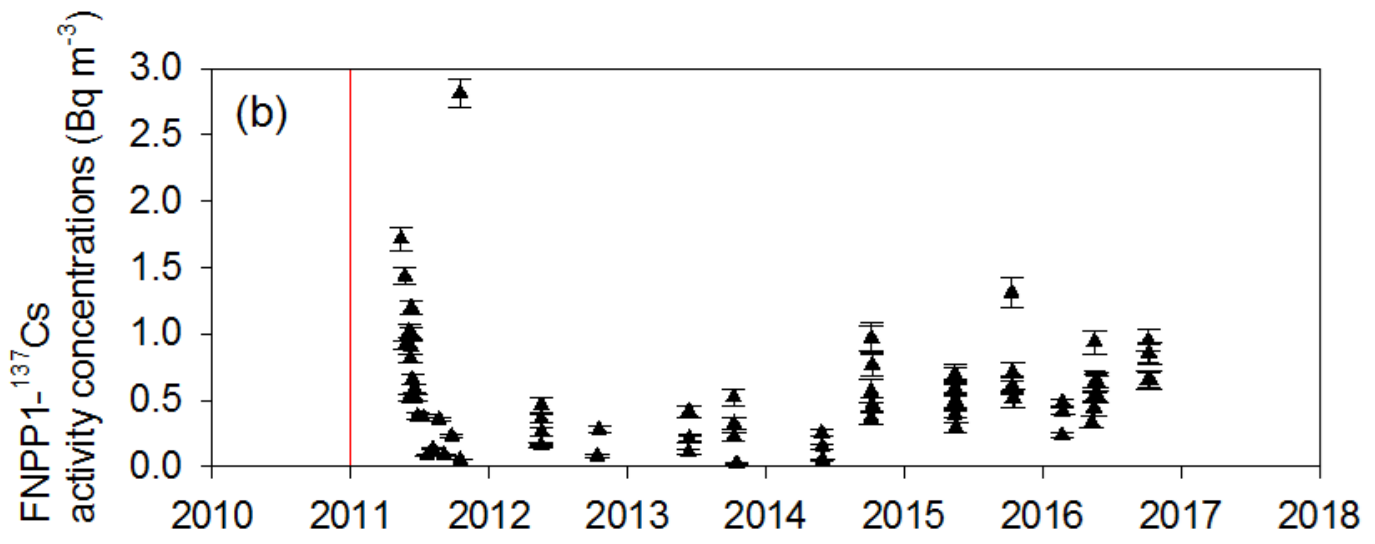

30 Fig. S9. Time variation of (a) ${ }^{137}$ Cs activity concentrations from 1980 to 2020, (b) enhanced ${ }^{137}$ Cs activity concentrations based on the fitting curve shown in Figure SI1 at Aomori area. The value was decay corrected to $11^{\text {th }}$ March 2011. Vertical red line mean the FNPP1 accident day (11 March 2011). 


\section{Tomari}

10

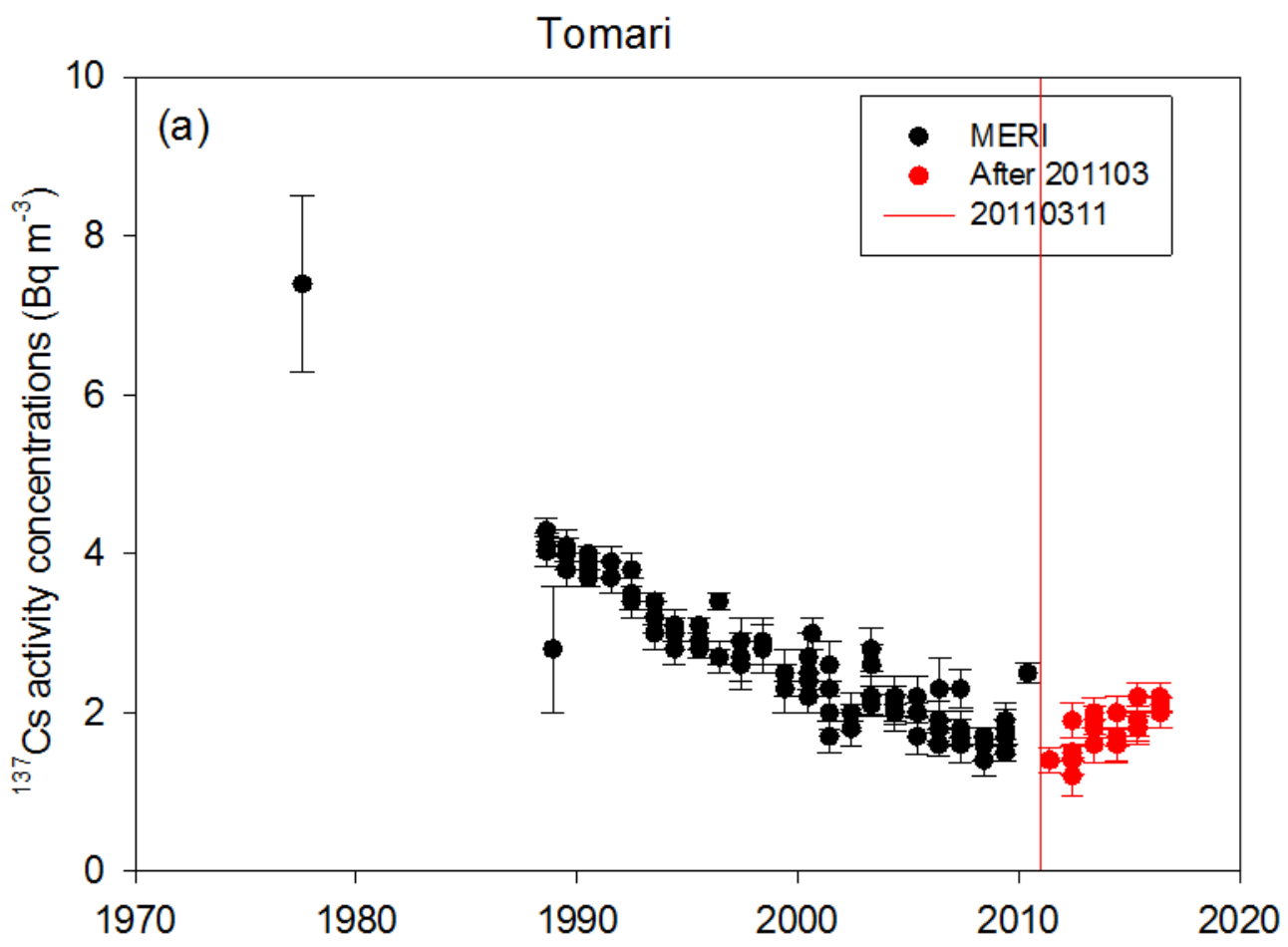

20

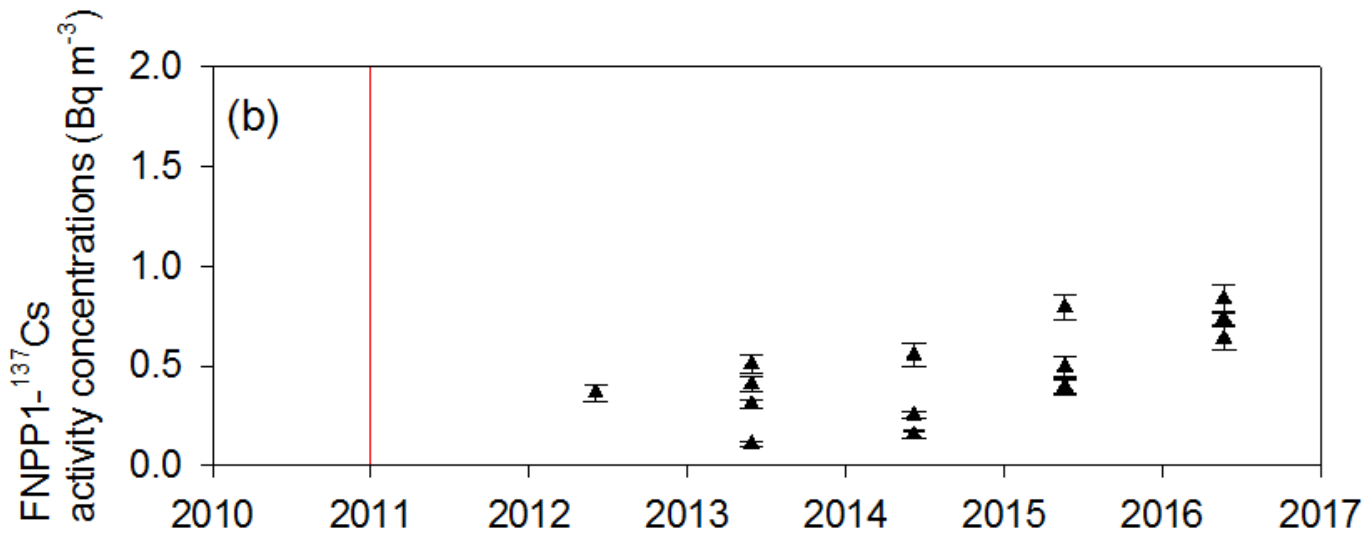

30

Fig. S10. Time variation of (a) ${ }^{137}$ Cs activity concentrations from 1970 to 2020, (b) FNPP1- ${ }^{137}$ Cs activity concentrations based on the fitting curve shown in Figure SI1 at Tomari. The value was decay corrected to $11^{\text {th }}$ March 2011. Vertical red line mean the FNPP1 accident day (11 March 2011). 

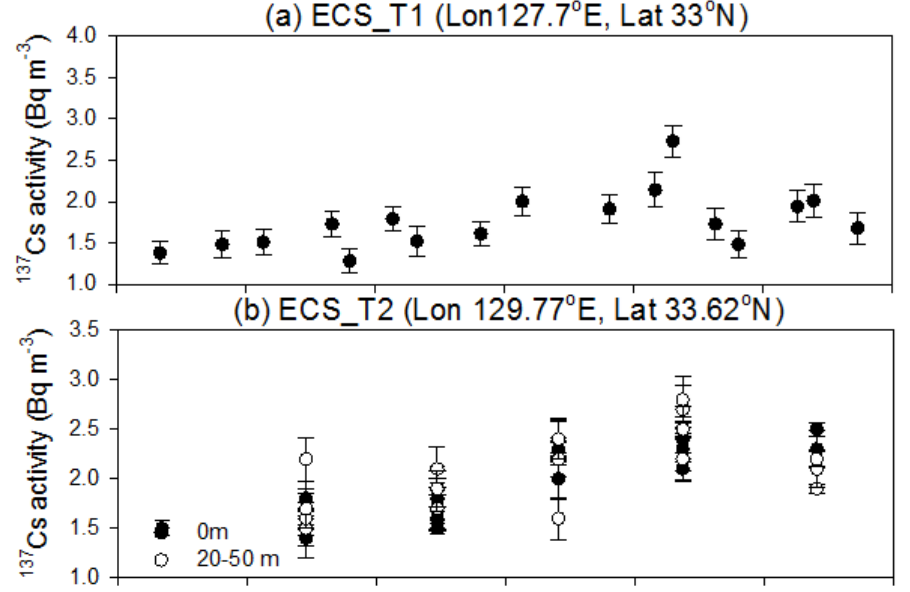

(c) ECS_T3 (Lon $130.02^{\circ} \mathrm{E}$, Lat $\left.31.75^{\circ} \mathrm{N}\right)$

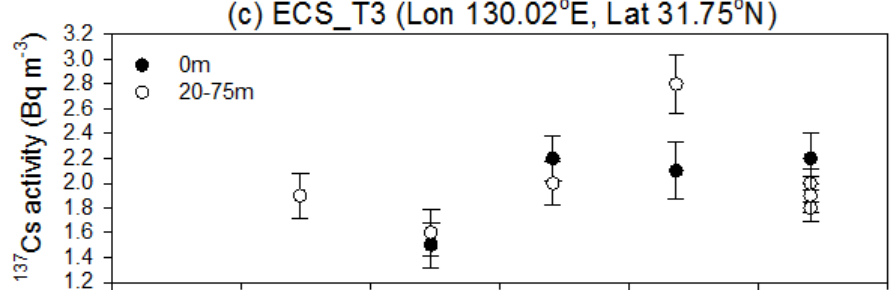

(d) ECS_T4 (Lon $130.07^{\circ} \mathrm{E}$, Lat $\left.31.68^{\circ} \mathrm{N}\right)$

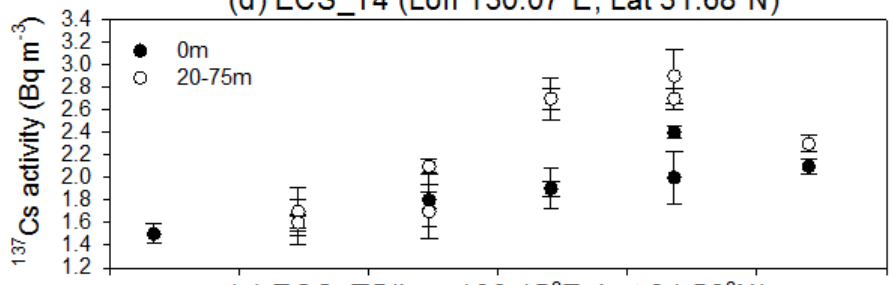

25

(e) ECS_T5(Lon $130.15^{\circ} \mathrm{E}$, Lat $\left.31.58^{\circ} \mathrm{N}\right)$

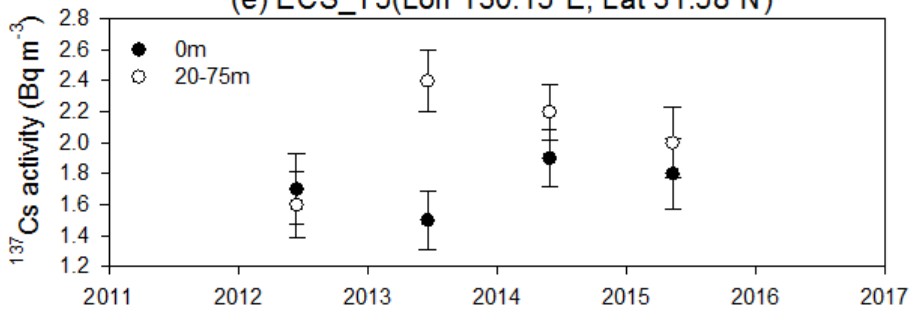

Fig. S11. Temporal variations of ${ }^{137}$ Cs activity concentrations at the five sites in ECS. (a) Longitude $127.7^{\circ} \mathrm{E}$, Latitude $33^{\circ} \mathrm{N}$, (b) Longitude $129.77^{\circ} \mathrm{N}$, Latitude $33.62^{\circ} \mathrm{N}$, (c) Longitude $130.02^{\circ} \mathrm{E}$, latitude $31.75^{\circ} \mathrm{N}$, (d) Longitude $130.07^{\circ} \mathrm{E}$, Latitude $31.68^{\circ} \mathrm{N}$, (e) Longitude $130.15^{\circ} \mathrm{N}$, Latitude $31.58^{\circ} \mathrm{N}$. These 35 are monitoring sites denoted as triangle with arrows in Fig. 6. 